\title{
PRÁTICAS DE LEITURA E DE ESCRITA NO IFG: DA PONTA DO LÁPIS AOS MULTILETRAMENTOS
}

\section{PRACTICES OF READING AND WRITING IN IFG: FROM THE TIP OF THE PENCIL TO THE MULTILITERACIES}

\author{
Dalva Ramos de Resende Matos * \\ Pauliana Duarte Oliveira ${ }^{* *}$ \\ Selma Zago da Silva Borges ${ }^{* * *}$
}

\begin{abstract}
Resumo: Além da missão de qualificar profissionais para os diversos setores da economia, os Institutos Federais de Educação, Ciência e Tecnologia também primam pela formação de sujeitos críticos e reflexivos, proporcionando aos estudantes eventos de letramentos, com vistas ao exercício pleno da cidadania. Nessa perspectiva, este trabalho visa socializar um relato de experiência referente ao Projeto de Ensino Multiletramentos, desenvolvido no Instituto Federal de Goiás - Câmpus Itumbiara, nos quatro últimos anos. Tal projeto didático-pedagógico, de caráter interdisciplinar, tem como principal propósito contribuir com a aprendizagem de leitura e de escrita dos alunos do ensino médio integrado ao técnico em regime integral da Rede Federal, a partir de práticas baseadas, principalmente, na teoria bakhtiniana dos gêneros do discurso e na Pedagogia dos Multiletramentos. Dados os resultados positivos alcançados com essa experiência, espera-se que este trabalho possa contribuir com a discussão em prol de uma educação linguística no âmbito da Rede Federal.
\end{abstract}

Palavras-chave: Leitura. Escrita. Gêneros do discurso. Multiletramentos. Interdisciplinaridade.

Abstract: Besides the mission of qualifying professionals for several sectors of the economy, the Federal Institutes of Education, Science, and Technology also excel for the formation of critical and reflexive subjects, providing events of literacy to the students, with sights on the full exercise of the citizenship. In this perspective, this work aims to socialize a report of experience referring to the Teaching Project Multiliteracies, developed in the Federal Institute of Goiás - Câmpus Itumbiara, in the last four years. Such a pedagogic-educational project, of interdisciplinary character, has as the main purpose to contribute with the apprenticeship of reading and writing of the pupils of the high school integrated to the technical courses in full time of the Federal Network, from practices founded, mainly, in the bakhtinianian theory of the speech genres and the Pedagogy of the Multiliteracies. Due to the positive results reached with this experience, it is expected that this work could contribute to the discussion in behalf of linguistic education in the context of the Federal Network.

Keywords: Reading. Writing. Speech genres. Multiliteracies. Interdisciplinarity.

\footnotetext{
* Doutoranda em Educação pela Universidade de Santiago de Compostela (USC) - Espanha. Participa como investigadora em formação do Grupo Literatura gallega. Literatura Infantil y Juvenil. Investigaciones literarias, artísticas, interculturales y educativas (USC). Professora efetiva do Instituto Federal de Goiás (IFG) - Câmpus Itumbiara. E-mail: dalva.matos@ifg.edu.br

** Doutora em Estudos Linguísticos pela Universidade Federal de Uberlândia (UFU). Professora efetiva do Instituto Federal de Goiás (IFG) - Câmpus Itumbiara. E-mail: pauliana.oliveira@ifg.edu.br

*** Doutora em Estudos Linguísticos pela Universidade Federal de Uberlândia (UFU). Professora efetiva do Instituto Federal de Goiás (IFG) - Câmpus Itumbiara. E-mail: selma.zago@ifg.edu.br
} 
Primeiras palavras: começo de conversa

A essência da linguagem nessa ou naquela forma, por esse ou aquele caminho se reduz à criação espiritual do indivíduo (BAKHTIN, 2003, p. 270).

A escrita que aqui se apresenta, sob a escolha inicial da epígrafe bakhtiniana, revela a posição das autoras para proferir a linguagem e os sujeitos que nela se constituem e, em consequência disso, mostrar o(s) caminho(s) percorrido(s) para compreender as possibilidades de conhecer esse objeto de estudo. Feito isso, este trabalho tem por objetivo geral socializar um relato de experiência relativo ao Projeto de Ensino Multiletramentos, intitulado de $A$ arte da arte da "leitura-escrita": das receitas aos improvisos criativos que em suspiros dos riscos se descomplicam em pautas, desenvolvido nos últimos quatro anos (2016 a 2019), no Instituto Federal de Goiás (IFG) - Câmpus Itumbiara, de autoria e coordenação das autoras deste artigo.

Parte-se da premissa de que, além da missão de qualificar profissionais para os diversos setores da economia - no âmbito técnico e tecnológico -, os Institutos Federais de Educação, Ciência e Tecnologia, pertencentes à Rede Federal, também primam pela formação de sujeitos críticos e reflexivos. Nessa perspectiva, cabe à escola, enquanto principal agência de letramentos (KLEIMAN, 1995), proporcionar aos estudantes eventos que contribuam para o desenvolvimento de práticas sociais de leitura, escrita e oralidade de gêneros do discurso/gêneros textuais ${ }^{1}$ de diferentes esferas/campos de atividade/comunicação/uso da linguagem, com vistas ao exercício pleno da cidadania. ${ }^{2}$

Ademais, cabe à Rede Federal, no que tange à oferta de cursos técnicos integrados ao ensino médio, contemplar os dispositivos legais contidos na Lei de Diretrizes e Bases da Educação Nacional (LDBEN), que estabelece, no art. 22, que "a educação básica tem por finalidade desenvolver o educando, assegurar-lhe a formação comum para o exercício da cidadania e fornecer-lhe meio para progredir no trabalho e em estudos posteriores" (BRASIL, 1996).

Tendo em vista esses pressupostos, o Projeto de Ensino Multiletramentos, de caráter interdisciplinar, vem buscando, ao longo de suas quatro edições (2016 a 2019) ${ }^{3}$,

\footnotetext{
${ }^{1}$ Apesar de este trabalho mobilizar a noção de gêneros do discurso de Bakhtin (2003), ele trata de atender a diferentes demandas, como a de subsidiar espaços/grupos de estudo e de problematização sobre práticas educacionais em contextos socioescolares. Nesse sentido, considera-se importante a justificativa sobre a escolha pelos termos gêneros do discurso/gêneros textuais. Ela se sustenta em razão de um número significativo de trabalhos teóricos que mobilizam tais termos e, mais precisamente, da presente oscilação entre eles nesses estudos. Ademais, essa escolha também se apoia em razão de que, no campo das políticas públicas que normatizam e norteiam a educação básica brasileira, não há consenso quanto à opção e/ou à prevalência de um dos termos, tendo em vista a ocorrência hesitante nos diferentes documentos oficiais, como a BNCC - Base Nacional Comum Curricular (BRASIL, 2017) e a Matriz de Referência Enem. Disponível em: http://download.inep.gov.br/download/enem/matriz referencia.pdf. Acesso em: 8 jun. 2020.

${ }^{2}$ Também em decorrência do exposto na nota anterior, a ocorrência, em simultaneidade, dos termos "esfera" e "campo", bem como de "atividade/comunicação/uso", leva em consideração tanto os aportes teóricos no qual se sustenta este estudo, a saber, a definição de gêneros do discurso em Bakhtin (2003), quanto os dispositivos legais, normativos, conforme a BNCC (BRASIL, 2017).

${ }^{3}$ Destaca-se que, em 2020, em razão do atual cenário brasileiro e mundial de pandemia de Covid-19, está em desenvolvimento uma proposta piloto do Projeto de Ensino Multiletramentos, em regime especial de ensino não presencial, com o desenvolvimento das oficinas em ambientes virtuais de ensino e de aprendizagem.
} 
contribuir com essa formação, por meio do ensino de práticas inovadoras de leitura e de escrita, na perspectiva bakhtiniana dos gêneros do discurso e da Pedagogia dos Multiletramentos. Metodologicamente, o projeto propõe o desenvolvimento de oficinas, como uma estratégia de mobilização, a fim de proporcionar aos participantes oportunidades de ensino e de aprendizagem que os capacitem para situações efetivas de trabalho com a leitura e a escrita, incluindo, a proficiência nas provas de Linguagens e de Redação do Exame Nacional do Ensino Médio, doravante Enem, cujas notas são utilizadas em grande parte dos processos seletivos de acesso ao ensino superior.

Isso posto, para uma melhor compreensão do Projeto de Ensino Multiletramentos, este trabalho traz a seguir: a sua base teórica, com sustentação principalmente nos autores Bakhtin (2003), Rojo (2009, 2017) e Rojo e Barbosa (2015); a apresentação geral e discussão do projeto, tendo em vista, principalmente, a justificativa, os objetivos e os procedimentos didático-metodológicos; e as considerações finais, com vistas aos principais resultados alcançados e algumas perspectivas.

1 Uma conversa afiada: do letramento e suas ramificações aos gêneros do discurso/gêneros textuais

As práticas de leitura e de escrita na atualidade não são mais as mesmas de antes, haja vista as inúmeras transformações ocorridas em nossas sociedades. Segundo Cassany (2006), a escrita e as formas de lê-la acompanham as evoluções das comunidades. Para esse autor espanhol, assim como houve mudanças, por exemplo, nos meios de comunicação e nas indústrias, com o surgimento da Internet e da automação robótica, os discursos também evoluíram com a implantação e o desenvolvimento da democracia, com a globalização que propiciou o contato com representantes de outras línguas e culturas, com as novas tecnologias e com os avanços científicos.

Tais mudanças acarretaram novas práticas de leitura e de escrita, fazendo surgir novas teorias, como as dos New Literacy Studies, doravante NLS, Novos Estudos do Letramento (NEL), em português, que atribuem à escola o papel fundamental de ampliar o letramento dos alunos, a fim de que eles possam desenvolver práticas sociais e culturais de leitura e de escrita em diversos contextos, com vistas ao exercício pleno da cidadania. Essas práticas, como socialmente construídas, começaram a ser pesquisadas a partir da década de 1970, com os NLS, a partir de uma vertente sociointeracionista, como um contraponto aos antigos estudos sobre literacy ${ }^{4}$. Tal proposta provocou uma ressignificação dessa palavra, com o intuito de rever tanto as abordagens teóricometodológicas sobre o uso da escrita, quanto as políticas de alfabetização, pautadas, ainda naquela época, em pressupostos evolucionistas de uma polarização entre letrados e iletrados. Esse movimento, "entre outros, fez parte da chamada 'virada social', a qual marcou uma mudança de foco das pesquisas sobre a língua escrita - antes centradas na escritura do indivíduo e sua mente - para a interação e para a prática social" (KLEIMAN; ASSIS, 2016, grifo das autoras, p. 30).

\footnotetext{
${ }^{4}$ Segundo Saito e Souza (2011, p.110, destaques dos autores): "O termo 'letramento' vem do inglês literacy (que por sua vez deriva-se filologicamente do latim littera, que quer dizer 'letra'). Em português, trata-se de uma palavra nova, tomada de empréstimo ou criada a partir do termo da Língua Inglesa. Literacy, em inglês, designa ao mesmo tempo alfabetização, ou seja, um conjunto de habilidades cognitivas e mecânicas de apreensão do código da escrita (aquisição de litterae), bem como as práticas sociais de leitura e escrita desenvolvidas após ou paralelamente à alfabetização".
} 
Quanto aos pressupostos teóricos dessa nova proposta de investigação, a obra do antropólogo inglês Street (1984), tida como seminal no campo, apresentou dentre outros construtos importantes, os conceitos de práticas e eventos de letramento. De acordo com o Glossário Ceale, tais conceitos são modelos analíticos estreitamente ligados. Todavia, o primeiro deles a ser construído, na perspectiva dos NLS, foi o de evento de letramento, por Heath (1982), que o caracterizou como sendo qualquer situação concreta em que o uso da escrita e/ou da leitura é constitutivo da interação e dos processos interpretativos dos sujeitos. Trata-se, portanto, "de um modelo analítico para descrever e caracterizar quando, onde e como as pessoas leem ou escrevem, conversam sobre um texto escrito ou interagem por meio da escrita" (STREET; CASTANHEIRA, 2014, on-line), dentro e fora da escola, como a situação de uma discussão oral em sala de aula sobre um livro de literatura lido pela turma ou quando as pessoas leem, em casa ou no banco de uma praça, os classificados de um jornal em busca de um emprego.

A partir dessa proposição, Street (1993, apud VIANNA et al., 2016, p. 32), elaborou o seguinte conceito de práticas de letramento:

[...], a noção de práticas de letramento deve ser entendida como um conceito amplo, que se lança em um nível de abstração e se refere tanto às ações dos sujeitos quanto a conceituações por eles elaboradas, ambas relacionadas ao uso de escrita e/ou da leitura (STREET, 1993). Dessa forma, investigar as práticas de letramento envolve o conceito de evento de letramento, ou seja, as situações de uso da escrita, às quais se acrescentariam os valores, as crenças, os discursos sobre a escrita, as atitudes e as construções sociais dos participantes dessas situações de escrita. Em síntese, essas práticas estão imersas (e são expressas) em uma forma de pensar, valorizar, sentir e usar a escrita.

No contexto educacional brasileiro, o termo letramento surgiu nos anos 1980, associado à alfabetização, para designar uma aprendizagem inicial da língua na modalidade escrita que fosse além da aquisição do sistema alfabético e suas convenções, com a introdução às práticas sociais da cultura escrita. Magda Soares, especialista e pesquisadora na área de letramento e alfabetização, apresenta, no Glossário Ceale, a seguinte acepção:

Letramento: o desenvolvimento das habilidades que possibilitam ler e escrever de forma adequada e eficiente, nas diversas situações pessoais, sociais e escolares em que precisamos ou queremos ler ou escrever diferentes gêneros e tipos de textos, em diferentes suportes, para diferentes objetivos, em interação com diferentes interlocutores, para diferentes funções (SOARES, 2014, on-line).

É importante ressaltar que, segundo essa autora, existem vários níveis e tipos de letramento, podendo haver, inclusive, pessoas que, mesmo analfabetas, possuem um certo grau de letramento, e vice-versa. Por isso, práticas diferentes são vistas como letramento, embora sejam diferentemente valorizadas e designem a seus sujeitos poderes também diversos. Assim, segundo Hamilton (2002), há duas categorias interligadas: letramentos dominantes institucionalizados e letramentos locais vernaculares. Os primeiros estão associados a organizações formais (escola, igrejas, local de trabalho, burocracias) e preveem agentes valorizados legal e culturalmente em relação ao 
conhecimento (professores, pesquisadores, padres, juízes), como os mobilizados no Projeto de Ensino Multiletramentos. Já os letramentos vernaculares têm sua origem na vida cotidiana, nas culturas locais e, frequentemente, são desvalorizados pela cultura oficial, constituindo, muitas vezes, práticas de resistência.

Atualmente, o termo letramento sofre uma proliferação de ramificações que the dão um caráter polissêmico. Cosson (2015) entende que, numa tendência contemporânea, o termo exprime por um lado:

[...] uma nova compreensão da leitura e da escrita e das relações entre saberes e educação, e por outro, faz parte de um contexto, onde se postula um ensino por competências, as tecnologias de informação e comunicação se tornam mais acessíveis, o fluxo de informações se mundializa, as imagens adquirem status de texto, as práticas de autosserviço se tornam cotidianas e o acesso ao ensino superior chega a camadas menos favorecidas da sociedade, isso só para falar de alguns tópicos que fazem parte do horizonte [...] dos adjetivos que acompanham o termo letramento (COSSON, 2015, p. 175).

Dentre essas adjetivações, podem ser citados: letramento acadêmico, letramento ambiental, letramento crítico, letramento digital, letramento escolar, letramento financeiro, letramento literário, letramento matemático, letramento midiático, letramento social, letramento político, letramento visual, letramento em saúde, dentre outros exemplos. Ademais, diante do conjunto heterogêneo de práticas sociais de leitura e de escrita que circulam em nossa sociedade letrada, Paulino (2005, p. 56) defende o emprego de letramentos, alegando que a forma no plural explicita mais adequadamente "as diferenças entre as práticas de leitura, derivadas de seus múltiplos objetivos, formas e objetos, na diversidade também de contextos e suportes em que vivemos".

Nessa expansão, surgem também os letramentos múltiplos ou multiletramentos, com o prefixo pluralizador, que amplia o conceito para um sentido mais vasto de signos e símbolos. Dessa forma, desloca-se a "habilidade de ler e escrever para a capacidade de se comunicar, de fazer uso dos instrumentos de representação da linguagem, reconhecendo-se o impacto das novas tecnologias nas relações sociais e culturais contemporâneas" (COSSON, 2015, p. 177). Nessa vertente de ampliação do termo, destaca-se a teoria dos multiletramentos, que, de acordo com Rojo $(2009,2017)$ e Rojo e Barbosa (2015), compreendem as mais diversas formas de utilização da leitura e da escrita, envolvendo as culturas locais e seus agentes, em relação com os letramentos valorizados, universais e institucionais. Para Rojo (2009), os textos, atualmente, contemplam diversas linguagens: imagem, música e outras semioses, fazendo ampliar a noção de letramento.

Ainda segundo essa pesquisadora, esse movimento surgiu com um manifesto de professores e pesquisadores americanos por uma Pedagogia dos Multiletramentos nos Estados Unidos, em 1996. Nessa vertente, para a formação da cidadania em geral, apenas o livro impresso não basta. Por isso, nessa perspectiva, a escola não pode ignorar as novas mídias que tanto atraem as crianças e os jovens. Todas elas, televisão, rádio, mas, sobretudo, as mídias digitais, precisam ser incorporadas à prática escolar. Além do mais, levando-se consideração que a sociedade, atualmente, funciona por meio de múltiplas linguagens e de uma diversidade de culturas, a escola precisa abordá-las em tempos de hipermodernidade, multiletramentos e repertório infinito de gêneros do discurso/gêneros textuais. 
Como uma especificidade dos multiletramentos, surgiram os novos letramentos (ou letramentos digitais), como sendo um subconjunto definido pelas novas tecnologias, mas não essencialmente por elas.

$\mathrm{O}$ que define fundamentalmente os novos letramentos, segundo os autores (LANKSHEAR E KNOBEL, 2007), é um novo "ethos", isto é uma nova maneira de ver e de ser no mundo contemporâneo, que prioriza a interatividade, a colaboração e a (re)distribuição do conhecimento, ao invés da hierarquia, da autoria e da posse controlada e vigiada do conhecimento por diversas agências, como a escola, as editoras e a universidade (ROJO, 2017, p. 4, grifo da autora).

Nesse contexto do letramento aos novos letramentos, considera-se, atualmente, a heterogeneidade de linguagens como a condição básica para a proficiência dos estudantes em leitura, escrita e oralidade, por meio do acesso aos diferentes gêneros do discurso/gêneros textuais que circulam socialmente e que se materializam nas diferentes práticas sociais existentes em uma sociedade conectada. Essa variedade está presente também na escola (pelo menos, deveria), onde circula uma multiplicidade de tipos textuais e gêneros do discurso/gêneros textuais (orais, impressos, digitalizados e digitais) de outras esferas/campos, como a jornalística, a literária e a científica.

Nesse viés, o ensino de línguas (materna e estrangeira) considera a variedade (a heterogeneidade) de linguagens como a condição básica para a proficiência dos estudantes em leitura, escrita e oralidade, por meio do acesso aos diferentes gêneros do discurso/gêneros textuais em circulação. Assim, há uma relação entre multiletramentos e gêneros, uma vez que todo letramento é sempre um letramento em algum gênero e precisa ser determinado em relação aos sistemas de signos, aos recursos tecnológicos utilizados e aos contextos sociais de produção, circulação e emprego dos gêneros (LEMKE, 2010).

Além disso, as reflexões sobre os gêneros são antigas, remontam à Grécia Antiga, com a Poética e a Retórica, de Aristóteles, e vão até as teorias contemporâneas, iluminando questões de produção e circulação dos discursos, com destaque para a teoria bakhtiniana. Em função dessa relevância, alguns pontos da abordagem dos gêneros do discurso, de Mikhail Bakhtin, também norteiam o Projeto de Ensino Multiletramentos, sobretudo o que se refere aos seus elementos essenciais dos gêneros - conteúdo temático, estilo e construção composicional-, correlacionados às condições específicas e às finalidades de cada esfera de atividade humana:

\footnotetext{
O emprego da língua efetua-se em forma de enunciados (orais e escritos) concretos e únicos, proferidos pelos integrantes desse ou daquele campo da atividade humana. Esses enunciados refletem as condições específicas e as finalidades de cada referido campo não só por seu conteúdo (temático) e pelo estilo de linguagem, ou seja, pela seleção de recursos lexicais, fraseológicos e gramaticais da língua, mas, acima de tudo, por sua construção composicional (BAKHTIN, 2003, p. 261).
}

Nessa abordagem, o gênero não é tratado como um produto, mas focalizado pelo viés dinâmico da produção, sendo o ponto de partida o vínculo intrínseco entre a utilização da linguagem e a esfera de atividade. Para Bakhtin (2003, p. 262, grifo do autor), "cada campo de utilização da língua elabora seus tipos relativamente estáveis de enunciados, os quais denominamos gêneros do discurso", numa heterogeneidade tão 
ampla que é impossível catalogá-los. Essa diversidade (e também a sua riqueza) é infinita devido à variedade da atividade humana e porque, em cada esfera dessa atividade, há um repertório de gêneros do discurso, que aumenta e se diferencia à medida que a própria esfera se desenvolve e se complexifica. Essa variedade também está presente na esfera escolar, conforme dito anteriormente, onde circula uma multiplicidade de gêneros de diferentes esferas/campos (literária/o, jornalística/o, científica/o, acadêmica/o, artística/o etc.) como objeto de ensino.

Em função dessa diversidade e das múltiplas linguagens e culturas presentes na sociedade contemporânea, as instituições de ensino precisam abordá-las por meio de práticas inovadoras, como as implementadas no Projeto de Ensino Multiletramentos, a fim de que possam atender a tais demandas e contribuir para a formação plena dos cidadãos. Desse modo, a seguir, este texto trata de apresentar essa condição em meio à transposição do relato de uma prática.

20 cerne da conversa: da teoria à prática

O projeto em discussão abrange diferentes disciplinas, principalmente do eixo de Linguagens, Códigos e suas Tecnologias, com foco nas práticas de leitura e de escrita de textos em Língua Portuguesa baseadas, principalmente, no ensino dos gêneros do discurso/gêneros textuais, como também nas práticas de leitura com fins específicos de textos em línguas estrangeiras modernas (Inglês e Espanhol).

A ideia do projeto surgiu em 2016, em função, principalmente, de duas razões principais: a primeira se dá pela carência por parte dos(as) alunos(as) em relação ao domínio da leitura e da escrita na modalidade formal da Língua Portuguesa, o que inclui o conhecimento das convenções e das regras da norma culta (BRASIL, 2017), habilidades requeridas ao término da Educação Básica; a segunda, pela insignificante carga horária, de apenas um encontro semanal de 90 minutos, na área de Língua Portuguesa e Literatura oferecida aos alunos da Instituição nas duas últimas séries do Ensino Médio. Outro agravante é a ausência de oferta das disciplinas de Artes, Inglês e Espanhol, como disciplinas obrigatórias, no/a $3^{\circ}$ ano/série do ensino técnico integrado ao ensino médio e no $8^{\circ}$ período na modalidade de Educação de Jovens e Adultos (EJA).

Como proposta de intervenção para esse(s) problema(s), o projeto foi elaborado seguindo a instrução que regulamenta e normatiza os projetos de ensino no âmbito da Pró-Reitoria de Ensino do IFG, de acordo com o art. 2, da Instrução Normativa $n^{\circ} 03$, de 05 de setembro de $2016^{5}$, qual seja:

Projeto de Ensino constitui um conjunto de ações de intervenção e/ou de atividades didático-pedagógicas e supervisionadas de natureza integradora, de oferta temporária e preferencialmente inter/multi/transdisciplinar, destinadas exclusivamente aos discentes no âmbito de campus e/ou cada Departamento de Áreas Acadêmicas dos cursos técnicos integrados ao Ensino Médio e dos cursos superiores.

\footnotetext{
5 Instrução Normativa $n^{\circ} 03$, de 05 de setembro de 2016, que regulamenta e normatiza os projetos de ensino no âmbito do Instituto Federal de Educação Ciência e Tecnologia de Goiás - IFG e dá outras providências. Disponível em: http://ifg.edu.br/attachments/article/1397/in_proen_003_projetos_de_ensino.pdf. Acesso em: 23 maio 2020 .
} 
A partir dessa orientação, o projeto foi elaborado e coordenado por três professoras das disciplinas Língua Portuguesa e Literatura Brasileira, Inglês e Espanhol da instituição, contando com a colaboração de técnicos e docentes de outras áreas, como Artes, Jornalismo, Pedagogia e Sociologia. Numa perspectiva interdisciplinar, estabeleceu-se como objetivo geral: contribuir com o ensino de leitura e de escrita dos alunos dos cursos técnicos integrados ao ensino médio. Para atingir esse propósito geral, definiram-se os objetivos específicos, a saber:

i. Intensificar práticas de leitura e de escrita em Língua Portuguesa baseadas no ensino dos gêneros do discurso/ gêneros textuais, mais precisamente dos gêneros que se apresentam como aspectos tipológicos predominantes os textos da ordem do dissertar e do argumentar;

ii. Proporcionar aos estudantes oportunidades de ensino e aprendizagem que os capacitem para situações efetivas de trabalho com a leitura e a escrita, como o domínio satisfatório da produção escrita referente ao gênero redação no Enem;

iii. Oferecer aos participantes a oportunidade de desenvolvimento da leitura em língua estrangeira, Inglês e Espanhol, habilidade avaliada na prova do Enem avaliação externa de seleção para o ingresso no ensino superior brasileiro, por meio da utilização de estratégias de leitura, de compreensão e de interpretação de textos nessas línguas;

iv. Oportunizar aos discentes um espaço para aperfeiçoarem seus conhecimentos estéticos, em se tratando de saberes relativos à produção artística e à apreciação estética, conforme competências e habilidades requeridas no referido exame;

v. Possibilitar aos estudantes o emprego adequado de diferentes argumentos a partir de discussões e citações de autoridades de áreas interdisciplinares.

A fim de se atingir tais objetivos, em suas quatro edições, 2016, 2017, 2018 e 2019, o referido projeto adotou procedimentos didático-metodológicos de forma integradora e interdisciplinar, com a utilização de metodologias inovadoras em novos tempos e espaços escolares. Além da sala de aula, outros espaços físicos - como a biblioteca, o auditório e uma sala temática, denominada Sala de Linguagens - e virtuais vêm sendo utilizados para estudos individuais e em grupos.

Quanto à sua execução, nas quatro edições, o projeto caracterizou-se por encontros semanais realizados na própria instituição de ensino, em horários alternativos às aulas regulares dos inscritos. Cada encontro presencial, no formato de oficina, teve a duração de 90 minutos, seguido de propostas de atividades complementares extraclasse. Em cada edição do projeto, foi cumprida uma carga horária de 54 horas, no período de agosto a novembro de cada ano, finalizando-se sempre na última semana antes da aplicação do Enem. Nas três primeiras edições, foram oferecidas 25 vagas e, na última, em função da grande demanda, 38 vagas, preferencialmente, destinadas aos alunos do último ano do Ensino Médio. Mesmo com essa ampliação, sempre há uma lista de espera. Todavia, tal limite de vagas é necessário em função dos procedimentos quanto à metodologia das oficinas, já que essas compreendem, além da teoria, atividades práticas coletivas e em pequenos grupos, bem como atendimentos personalizados nos plantões de dúvidas. Dessa forma, um número alto de participantes inviabilizaria tais procedimentos.

Em se tratando basicamente das oficinas, intituladas de Oficinas Pré-Enem, é importante destacar que elas foram propostas como uma estratégia de mobilização de oportunidades de ensino e de aprendizagem, capacitando os participantes para situações 
efetivas de trabalho com a leitura e a escrita, como o domínio satisfatório da produção escrita referente às provas de Linguagens e Redação no Enem. Além disso, as oficinas, também, buscaram oferecer aos participantes a oportunidade de desenvolvimento das práticas de leitura em língua estrangeira, por meio do conhecimento da utilização de estratégias de leitura, de compreensão e de interpretação de textos em Espanhol e Inglês (LÓPEZ RAMÍRES, 2006; OLIVEIRA, 2000). Para ampliar a interdisciplinaridade, o projeto também tem procurado oportunizar aos discentes um espaço para aperfeiçoarem seus conhecimentos estéticos, em se tratando de saberes relativos à produção artística e à apreciação estética, conforme competências e habilidades requeridas no referido exame, além de discussões de cunho sociológico e jornalístico.

Sobre o desenvolvimento das atividades, foram utilizados diferentes procedimentos e recursos didático-metodológicos, como aulas expositivo-dialogadas, inclusive com docência compartilhada, leitura de diversos textos (verbais e não verbais) veiculados em vários suportes (impressos, audiovisuais e digitais), discussões orais, fóruns de discussão em grupos de redes sociais, exercícios de identificação dos elementos essenciais do gênero redação Enem, produção dos textos, feedback das correções em atendimentos coletivos e individuais, reescrita dos textos, aplicação de simulado da prova de Linguagens e de Redação do Enem, produção de um jornal-mural virtual, intitulado de Jojomulti - O jornal do jovem multiletrado., conforme figura ilustrativa apresentada a seguir.

Figura 1 - Ilustração da Homepage da página do jornal-mural virtual JOJOMULTI - O jornal do jovem multiletrado (2019).
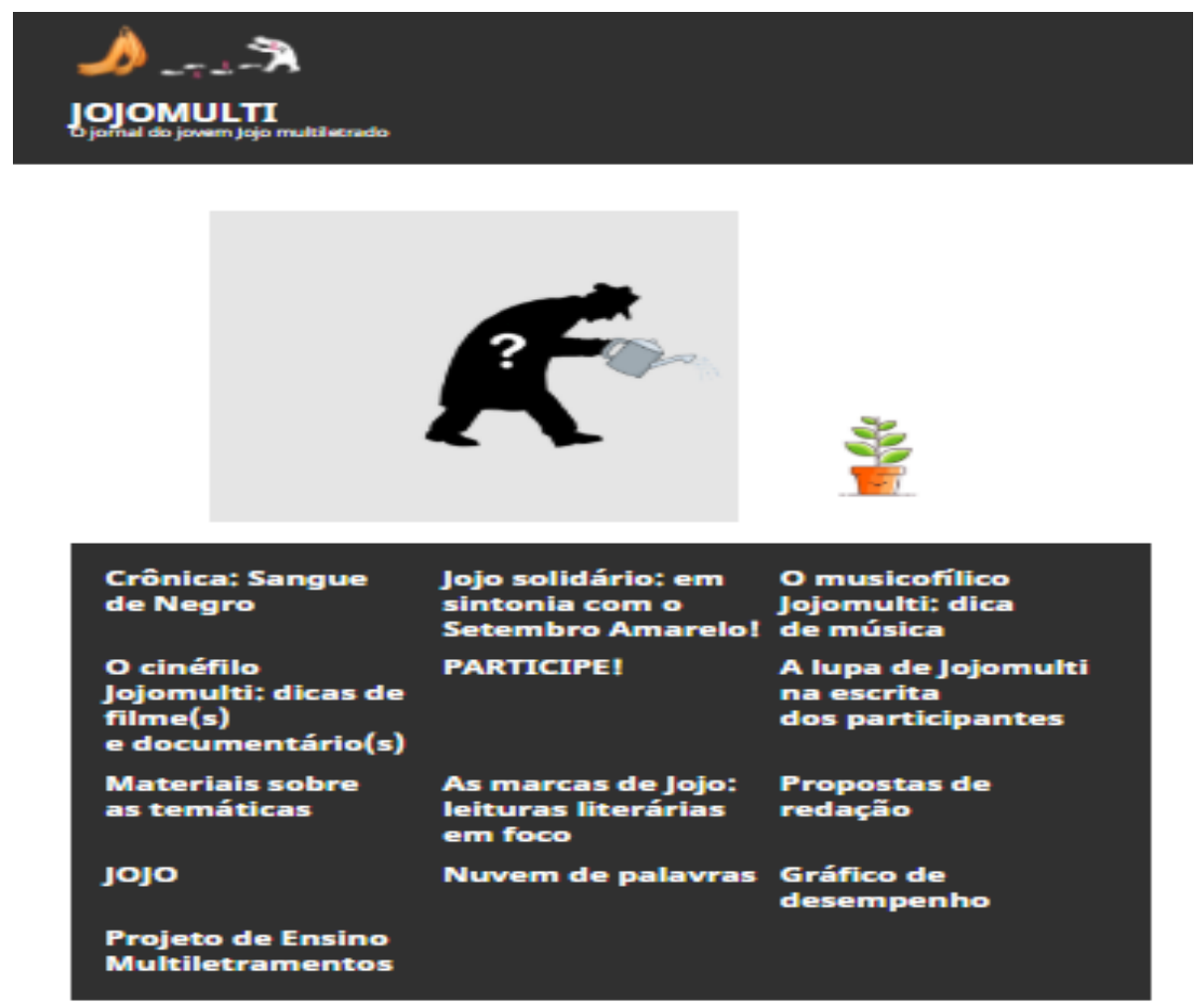

Fonte: Disponível em: https://jojomulti.home.blog/. Acesso em: 7 jun. 2020.

O Jojomulti foi uma criação piloto com fins de considerar e pôr em prática os diferentes e variados multiletramentos e novos letramentos, como aqueles relacionados 
às linguagens e mídias digitais. Assim, o Jojomulti veio à luz durante a realização do Projeto de Ensino Multiletramentos - Edição de 2019, diferenciando-a das edições anteriores do projeto, em termos de possibilidades de recursos didático-metodológicos oferecidos aos participantes. A equipe Multicom (equipe de comunicação), constituída por uma das professoras idealizadoras do projeto e três estudantes, dois bolsistas e um voluntário, teve por tarefa a produção desse jornal-mural virtual. O objetivo consistia em fomentá-lo com matérias variadas, por meio de diferentes postagens, e em consonância com a seleção de conteúdos temáticos trabalhados durante a efetiva realização das Oficinas Pré-Enem, a fim de possibilitar aos participantes a interação com diferentes gêneros e semioses nesse espaço digital e, em consequência, a ampliação do repertório sociocultural.

Destaca-se, também, que, no início de cada edição do projeto de ensino, traçouse um diagnóstico do perfil leitor dos estudantes, por meio da aplicação de um questionário sobre os hábitos de leitura dos participantes. Além disso, ao longo do desenvolvimento do projeto, ao término de cada encontro, os discentes fizeram uma avaliação das experiências vivenciadas durante a realização das oficinas, mediante o registro em um diário, intitulado de "Dos suspiros em pautas". No final de cada edição, os participantes fizeram também, por escrito, uma avaliação geral do projeto e uma autoavaliação do próprio desempenho durante o desenvolvimento do projeto. Baseandose nesses relatos, as professoras idealizadoras buscaram reestruturar as edições seguintes, quanto à dinâmica do trabalho, a fim de atender às demandas apresentadas e sugeridas pelos participantes.

Esses procedimentos didático-metodológicos, conforme apresentados, vão ao encontro da natureza e da caracterização dos projetos de ensino no âmbito do IFG, da Pró-Reitoria de Ensino, conforme art. 3, da Instrução Normativa $\mathrm{n}^{\mathrm{o}} 03$, de 05 de setembro de 2016: ${ }^{6}$

\begin{abstract}
As atividades de projetos de ensino são caracterizadas pelo desenvolvimento de metodologias diversificadas e diferenciadas, capazes de promover e possibilitar o aprofundamento e/ou a complementação de estudos dos núcleos comum, diversificado e específico e/ou a retomada de tópicos específicos do conteúdo programático de unidades curriculares, a partir do planejamento e da condução de atividades extraclasse, com orientação e avaliação de um ou mais professores responsáveis, podendo contar com a colaboração de outros servidores.
\end{abstract}

Especificamente, na edição de 2019, a proposta foi aprovada em um edital de seleção de projetos de ensino da Pró-Reitoria de Ensino da própria instituição, sendo contemplada com apoio financeiro para quatro estudantes bolsistas, que, juntamente com outros cinco estudantes voluntários, fizeram parte da equipe executora do projeto. Esses discentes, sob a orientação das professoras, desenvolveram atividades de monitoria, de assessoria tecnológica e de comunicação, em três equipes denominadas, respectivamente, de Multimon, Multitecsign e Multicom. Esta, conforme relatado anteriormente, ficou responsável pela produção do Jojomulti, dentre outras ações.

\footnotetext{
${ }^{6}$ Instrução Normativa $\mathrm{n}^{\mathrm{o}}$ 03, de 05 de setembro de 2016, que regulamenta e normatiza os projetos de ensino no âmbito do Instituto Federal de Educação, Ciência e Tecnologia de Goiás - IFG e dá outras providências. Disponível

em: http://ifg.edu.br/attachments/article/1397/in_proen_003_projetos_de_ensino.pdf. Acesso em: 23 maio 2020.
} 
De modo particular, em relação à leitura e à produção textual, o projeto pautou-se em uma proposta de ensino que não considera apenas o "treino" (como um discurso, no espaço socioescolar, amplamente propagado, como "treinar o aluno para o Enem"). Para isso, considerou-se producente para o ensino de leitura e de escrita tomar o gênero como (a)mostra (BORGES, 2016, p. 21), "pois a exposição do aluno a um modelo de gênero e não a uma (a)mostra revela-nos que a escola predominantemente reproduz um padrão de texto que se enquadraria em um protótipo textual que se torna instrumento regulador da produção escrita do aluno", enquanto que na perspectiva da (a)mostra, "o gênero é, ao mesmo tempo, um modelo e uma transgressão, [...] de modo a torná-la inteligível e ressaltar aquilo que é da ordem de um modelo (o iterativo: o recorrente) e de uma transgressão (o inventivo: a criação)" (p. 34, grifo da autora). Borges (2016) ainda considera que o gênero se define na relação com um conjunto de textos que compõem um corpus. Logo, somente é possível reconhecer um gênero e tornar, de algum modo, possível ensiná-lo a partir da relação que um gênero estabelece com outro gênero.

Mas como em cada contexto histórico-cultural, são favorecidas determinadas formas expressivas em detrimento de outras (Brandão, 2011), no referido projeto de ensino, foram priorizados os gêneros do discurso/gêneros textuais da ordem do dissertar (expor) e do argumentar (DOLZ; NOVERRAZ; SCHNEUWLY, 2004) ${ }^{7}$. Assim, no que se refere à produção de texto na modalidade escrita, a efetiva realização do trabalho considerou o texto dissertativo-argumentativo, em caráter de atender a uma demanda institucional de ensino, como consta nos documentos oficiais em circulação e disponíveis para os discentes e os docentes (Brasil, 2019), já que o Enem exige a produção de um texto dissertativo-argumentativo, conforme definição a seguir:

O texto dissertativo-argumentativo é aquele que se organiza na defesa de um ponto de vista sobre determinado assunto. É fundamentado com argumentos, a fim de influenciar a opinião do leitor, tentando convencê-lo de que a ideia defendida está correta. É preciso, portanto, expor e explicar ideias. Daí a sua dupla natureza: é argumentativo porque defende uma tese, uma opinião, e é dissertativo porque utiliza explicações para justificá-la. (BRASIL, 2019, p. 16, grifo nosso)

Assim, conforme recorte supracitado, tendo em vista a predominância das sequências dissertativa e argumentativa, essa definição pode ser sustentada no campo das tipologias textuais e/ou discursivas, que buscam a organização e a sistematização dos textos. $^{8}$ Nessa perspectiva, para Brandão (2011, p. 38), convém trabalhar o gênero

\footnotetext{
7 No trabalho intitulado de Sequências didáticas para o oral e a escrita: apresentação de um procedimento, os pesquisadores Dolz, Noverraz e Schneuwly (2004) tratam de apresentar aos variados leitores, estudiosos e pesquisadores um postulado que permite atender às exigências no que diz respeito ao ensino de produção oral e escrita. Para isso, a questão central da proposta apresentada por esses autores se caracteriza pelo procedimento sequência didática, tendo em vista o agrupamento de gêneros e progressão. Em se tratando especificamente dos agrupamentos, um de seus critérios diz respeito às capacidades de linguagem dominantes, a saber: narrar, relatar, argumentar, expor e descrever ações. Essa proposta tem sido bastante (re)visitada por estudiosos no Brasil, como também tem subsidiado a construção de documentos didático-pedagógicos institucionais.

${ }^{8}$ Para fins de esclarecimentos, há um número de teóricos, cujos estudos sobre o estudo das tipologias textuais e/ou discursivas se destacam, como Adam (1992), Bazerman (2005), Bronckart (2003), Schneuwly e Dolz (2004), dentre outros.
} 
"enquanto instituição discursiva, isto é, forma codificada sócio-historicamente por uma determinada cultura e [...] enquanto materialidade linguística que se manifesta em diferentes formas de textualização". Desse modo, ainda segundo essa autora, numa intersecção entre a análise do discurso e a linguística textual, é possível ao professor trabalhar, de forma proveitosa, com o conceito de gênero do discurso proposto por Bakhtin (2003) juntamente com a classificação de tipologias textuais cognitivas de Adam (1992), baseada em cinco tipos de estruturas sequenciais: narração, descrição, argumentação, explicação e diálogo.

Nesse sentido, o Projeto de Ensino Multiletramentos vai além da perspectiva tipológica do texto dissertativo-argumentativo, pois considera que a produção textual no Enem se caracteriza em gênero do discurso/gênero textual redação Enem, uma vez que, essa escrita, segundo Borges e Agustini (2013, p. 16), "revela que o candidato parte de uma experiência de linguagem em uma prática social efetiva e com fins bem delineados, como o acesso à Universidade, ao certificado de conclusão da educação básica, e a outros programas subsidiados pelo Governo Federal". Além disso, essa proposta de redação contempla os elementos essenciais - conteúdo temático, forma composicional e estilo - do gênero do discurso (Bakhtin, 2003), que devem ser observados pelos participantes, conforme orientações apresentadas em Redação no Enem 2019 - Cartilha do Participante:

\begin{abstract}
A prova de redação exigirá de você a produção de um texto em prosa, do tipo dissertativo-argumentativo, sobre um tema de ordem social, científica, cultural ou política.[...]; Compreender a proposta de redação e aplicar conceitos das várias áreas de conhecimento para desenvolver o tema, dentro dos limites estruturais do texto dissertativo-argumentativo em prosa; A redação receberá nota 0 (zero) se apresentar uma das características a seguir: fuga total ao tema; não obediência à estrutura dissertativoargumentativa; [...] (BRASIL, 2019, p. 5-7, grifo nosso).
\end{abstract}

Em suma, tomando todas essas posições, é importante destacar que o projeto de ensino trata de apresentar o modo como as ações didático-metodológicas se efetivam no espaço socioescolar, na sala de aula e, por conseguinte, na realização das oficinas de leitura e de escrita. Trata-se, portanto, de uma transposição teórica para esse lugar social e institucional, onde se configura numa relação tríade aluno-professor-ensino de leitura e de escrita. Dessa forma, o trabalho não se caracteriza como um cursinho preparatório para o Enem. Mais que conteúdo, treino e dicas para se fazer uma boa prova, o projeto vem se preocupando em aplicar teorias contemporâneas e metodologias inovadoras na prática escolar, a fim de contribuir para a formação acadêmica e integral dos participantes, capacitando-os para o exercício da cidadania, por meio de práticas sociais de leitura e de escrita.

Fim de conversa: resultados e aberturas para possíveis perspectivas e apostas ${ }^{9}$

Em linhas gerais, o Projeto de Ensino Multiletramentos, em suas quatro edições, atingiu resultados bastante positivos, uma vez que proporcionou aos alunos inscritos

\footnotetext{
9 “Apostas" no sentido de que há sempre a possibilidade de (re)começo e (re)estruturação, porque, no processo de ensino e de aprendizagem, há a participação de sujeitos e, por isso, não há uma receita.
} 
oportunidades de ensino e de aprendizagem, capacitando-os para situações efetivas de trabalho com a leitura e com a escrita, como o domínio satisfatório da produção escrita referente à Redação e à prova de Linguagens do Enem.

Esse progresso pode ser comprovado pelos registros dos participantes no diário de experiências "Dos suspiros em pautas", pela (auto)avaliação aplicada na oficina de encerramento de cada edição do projeto, bem como pelo notável progresso dos discentes em relação ao domínio formal da leitura e da escrita e à ampliação da formação do repertório sociocultural desses sujeitos demonstrados nas inúmeras atividades de interpretação textual e redações aplicadas ao longo das oficinas. Ademais, os participantes vêm obtendo resultados acima da média nacional no Enem e, consequentemente, sendo aprovados em diversos cursos de renomadas universidades públicas e particulares do país. ${ }^{10}$

Diante desses resultados, espera-se dar continuidade a esse trabalho nos próximos anos letivos, inclusive dentro da tríade: ensino, pesquisa e extensão. Em relação a esta, a equipe idealiza propor, por meio de reformulações necessárias, um curso de extensão voltado para a formação de professores da rede pública estadual, com o intuito de que esse público-alvo possa colocar em prática, em seus espaços de ensino e de aprendizagem, as propostas desenvolvidas no Projeto de Ensino Multiletramentos, constituindo, assim, uma possibilidade de atender a demandas específicas de seus contextos escolares. Portanto, essa proposta de extensão com vista à formação docente pretende propiciar a esses educadores subsídios teórico-metodológicos para a formação de comunidades de docentes e discentes leitores e escritores. Quanto à pesquisa, está em processo de criação um núcleo para implementação de ações de investigação articuladas a esse projeto de ensino já consolidado.

Por fim, com a divulgação de trabalhos em eventos acadêmico-científicos e com a publicação de artigos em periódicos, espera-se, também, continuar contribuindo para a discussão de trabalhos sobre metodologias inovadoras, de natureza integradora, no ensino e na avaliação da leitura e da produção textual no ensino médio. O trabalho é árduo, mas o caminho é possível.

\section{Referências}

ADAM, J.-M. Les textes: types et prototypes. Lausanne: Nathan, 1992.

BAKHTIN. M. M. Estética da criação verbal. Tradução de Paulo Bezerra. 4. ed. São Paulo: Martins Fontes, 2003.

BAZERMAN, C. Gêneros textuais, tipificação e interação. Organizado por Ângela Paiva Dionísio e Judith Chambliss Hoffnagel. Traduzido e adaptado por Judith Chambliss Hoffnagel. São Paulo: Cortez, 2005.

\footnotetext{
${ }^{10}$ A título de esclarecimento, em referência aos resultados de desempenho das escolas nas edições 2016, 2017 e 2018 do Enem, o IFG - Câmpus Itumbiara classificou-se em $1^{\circ}$ lugar entre as instituições escolares públicas (estaduais, federais e municipais) de Goiás. Já no último ano, os principais resultados dos participantes do projeto podem ser conferidos na matéria Ex-alunos do Câmpus Itumbiara se destacam em aprovações de vestibulares renomados pelo País, disponível em: https://www.ifg.edu.br/aluno/170-ifg/campus/itumbiara/noticias-campus-itumbiara/17045-alunoscampus-aprovacao-vestibular-2020. Acesso em: 22 maio 2020.
} 
BORGES, S. Z. S. A escrita da escrita em (d)enunciação no espaço sócio-escolar: um espaço (em vão) para a (cri)atividade escrita. 2015. 312 f. Tese (Doutorado em Estudos Linguísticos) - Universidade Federal de Uberlândia, Uberlândia, 2015.

BORGES, S. Z. S. ; AGUSTINI, C. L. H. Gênero redação ENEM: a experiência de linguagem em uma escrita institucionalizada. Letras \& Letras (Online), v. 29, p. 1-18, 2013.

BRANDÃO, H. N. Texto, gêneros do discurso e ensino. In: BRANDÃO, H. N. (coord.). Gêneros do discurso na escola. 5. ed. São Paulo: Cortez Editora, 2011. p. 1745.

BRASIL. Lei no 9394, de 20 de dezembro de 1996. Estabelece as diretrizes e bases da Educação Nacional. Diário Oficial [da] República Federativa do Brasil. Brasília, DF, 23 dez. 1996.

BRASIL. Secretaria da Educação Média e Tecnológica. PCN + Ensino médio: orientações educacionais complementares aos parâmetros curriculares nacionais. Brasília: MEC, 2002. 244p.

BRASIL. Ministério da Educação. Base Nacional Comum Curricular (BNCC). Brasília: MEC, 2017.

BRASIL. Instituto Nacional de Estudos e Pesquisas Educacionais Anísio Teixeira (Inep). A redação no Enem 2019: cartilha do participante. Brasília, 2019.

BRONCKART, J.-P. Gêneros textuais, tipos de discursos e operações psicolinguísticas. Revista de Estudos da Linguagem. Belo Horizonte, v. 11, n. 1, p. 49-69, 2003.

CASSANY, D. Tras las líneas: sobre la lectura contemporánea. Barcelona: Anagrama, 2006.

COSSON, R. Letramento literário: uma localização necessária. Letras \& Letras. v. 31, n. 3, p. 173-187, jul. 2015.

DOLZ, J.; NOVERRAZ, M.; SCHNEUWLY, B. Sequências didáticas para o oral e a escrita: apresentação de um procedimento. In: SCHNEUWLY, B..; DOLZ, J. e colaboradores. Gêneros orais e escritos na escola. Tradução e organização de Roxane Rojo e Glaís Sales Cordeiro. Campinas-SP: Mercado de Letras, 2004, p. 95-128.

HAMILTON, M. Sustainable literacies and the ecology of lifelong learning. In: HANSON, A.; CLARKE, J. (org.) Supporting lifelong learning, v.1: Perspectives on Learning. Routledge/Open University Press, 2002, p. 176-187.

HEATH, S. B. What no bedtime story means: narrative skills at home and school. Language and Society, 11, 1, p. 49-76, abr. 1982. 
KLEIMAN, A. B. (Org.). Os significados do letramento: uma nova perspectiva sobre a prática social da escrita. Campinas, SP: Mercado de Letras, 1995.

KLEIMAN, A. B.; ASSIS, J. A. (org.). Significados e ressignificações do letramento: desdobramentos de uma perspectiva sociocultural sobre a escrita. Campinas: Mercado de Letras, 2016.

LEMKE, J. L. Letramento metamidiático: transformando significados e mídia. Revista Trabalhos em Linguística Aplicada, 49, 2, p. 455-479, jul. 2010.

LÓPEZ RAMÍREZ, A. Estrategias de lectura: curso de actualización para profesores de español. Maringá: Embajada de España en Brasil, 2006.

OLIVEIRA, N. A. de. Para ler em inglês: desenvolvimento da habilidade de leitura. Belo Horizonte: N. O. S. Tec. Educ. Ltda, 2000.

PAULINO, G. Algumas especificidades da leitura literária. In: PAIVA, A.; MARTINS, A.; PAULINO, G.; VERSIANI, Z. (org.). Leituras literárias: discursos transitivos. Belo Horizonte: Autêntica, 2005, p. 55-68.

ROJO, R. H. R. Letramentos múltiplos, escola e inclusão social. São Paulo: Parábola Editorial, 2009.

ROJO, R. H. R. Entre Plataformas, ODAs e Protótipos: Novos multiletramentos em tempos de WEB2. The Especialist, v. 38, n. 1, p. 1-20, jan./jul. 2017. D

ROJO, R. H. R.; BARBOSA, J. P. (org.) Hipermodernidade, multiletramentos e gêneros discursivos. São Paulo: Parábola Editorial, 2015.

SAITO, F. S.; SOUZA, P. N. (Multi)letramento(s) digital(is): por uma revisão de literatura crítica. Linguagens e diálogos, v. 2, n. 1, p. 109-143, 2011.

SCHNEUWLY, B.; DOLZ, J. Gêneros orais e escritos na escola. Tradução e organização de Roxane Rojo e Glaís Sales Cordeiro. Campinas-SP: Mercado de Letras, 2004.

SOARES, M. B. Letramento e escolarização. In: RIBEIRO, V. M. (org.). Letramento no Brasil. São Paulo: Global, 2003, p. 89-113.

SOARES, M. B. Letramento: um tema em três gêneros. Belo Horizonte: Autêntica, 2009.

SOARES, M. B. Alfabetização e literatura. Revista Educação. Guia da Alfabetização, São Paulo, Editora Segmento, n. 2, p. 12-29, 2010.

SOARES, M. B. Letramento. In: FRADE, I. C. A.; COSTA VAL, da G.; BREGUNCI, M. G. C. (org.). Glossário Ceale: termos de alfabetização, leitura e escrita para educadores. Belo Horizonte: UFMG/Faculdade de Educação, 2014. 
STREET, B. V. Literacy in theory and practice. Cambridge: Cambridge University Press, 1984.

STREET, B. V.; CASTANHEIRA, M. L. In: FRADE, I. C. A.; COSTA VAL, da G.; BREGUNCI, M. G. C. (org.). Glossário Ceale - termos de alfabetização, leitura e escrita para educadores. Belo Horizonte: UFMG/Faculdade de Educação, 2014.

VIANNA, C. A. D.; SITO, L.; VALSECHI, C. M.; PEREIRA, S. L. M. Do letramento aos letramentos: desafios na aproximação entre letramento acadêmico e letramento do professor. In: KLEIMAN, A. B.; ASSIS, J. A. (org.). Significados e ressignificações do letramento: desdobramentos de uma perspectiva sociocultural sobre a escrita. Campinas: Mercado de Letras, 2016, p. 27-59.

Recebido em 28 de maio de 2020

Aceito em 06 de junho de 2020 